\title{
Supernumerary Philadelphia Positive Hyperdiploid Acute Lymphoblastic Leukemia: A Bad or A Good Prognosis? Single Case and Review of Literature
}

\author{
Nivedita Pathak ${ }^{1 *}$ and Akhilesh Mishra ${ }^{2}$ \\ ${ }^{1}$ Department of Pediatrics, All India Institute of Medical Sciences, India \\ ${ }^{2}$ Department of Radiation Oncology, VMMC \& Safdarjung Hospital, India
}

Submission: August 08, 2017; Published: September 06, 2017

*Corresponding author: Nivedita Pathak, Department of Pediatrics, All India Institute of Medical Sciences, New Delhi, India, Tel:01124644121; Email: nivisaiims@gmail.com

\begin{abstract}
Prognosis of ALL patients with Ph chromosome is known to be poor and that of hyper diploid karyotype is found to be good. Hyper diploid karyotype with supernumerary Philadelphia chromosome is a rarer entity. We are reporting a case of supernumerary Philadelphia chromosome positive, hyper diploid acute lymphoblastic leukemia and reviewing literature to find out the discrepancies in defining prognosis of such cases. Outcome heterogeneity changes according to chromosomal gain/loss in general so the challenge still remains. Such uncommon and atypical presentations have always been enigmatic as far as the correct approach to their clinical management is concerned. Should we need to move towards more individualized approach for better outcomes?
\end{abstract}

Keywords: Supernumerary philadelphia; Hyper diploidy; Acute lymphoblastic leukemia; Karyotype

\section{Introduction}

Philadelphia chromosome is observed in $25-50 \%$ of adult Acute Lymphoblastic Leukemia (ALL) cases and in about $5 \%$ of childhood ALL cases. A hyper diploid karyotype, defined by the presence of more than 46 chromosomes, is detected in $2-9 \%$ of adult ALL patients and in $29 \%$ of pediatric patients [1]. Translocation t $(9 ; 22)$ or Philadelphia chromosome is a common structural aberration found in patients, who present with hyper diploidy [2,3]. It is conceivable that the simultaneous presence of additional karyotypic abnormalities may alter the biological properties of $\mathrm{Ph}+$ cells and influence clinical outcomes [4]. In this context, the coexistence of a high-hyper diploid (53 chromosomes) karyotype with double $\mathrm{Ph}+$ chromosomes is of interest since high-hyper diploidy as the sole cytogenetic abnormality in ALL is associated with a good prognosis [4], while Philadelphia positivity confers a worse prognosis.

\section{Case Report}

A 41-year-old male presented with generalized body ache, low grade fever, swelling in neck and groin, anemia and thrombocytopenia. Physical examination revealed generalized (cervical, axillary and inguinal) lymphadenopathy and no splenomegaly. Testes were normal. Investigations revealed hemoglobin 7.6g/dL, a white blood cell count of 52 x 109/L with $50 \%$ blasts, and a platelet count of $19 \times 109 / \mathrm{L}$. Bone marrow aspirate was hyper cellular, with $70 \%$ blasts, which were negative for myeloperoxidase. Cytogenetic analysis of the patient's bone marrow cells was performed at the time of diagnosis. Bone marrow cells were cultured for $24 \mathrm{~h}$ without stimulation in RPMI 1640 supplemented with 20\% fetal calf serum and 1\% antibiotics. Metaphases were G-banded and the karyotype was described according to the ISCN 1995 [5]. 20 metaphases were analyzed which revealed the karyotype: $46, \mathrm{XY}, \mathrm{t}(9 ; 22)(\mathrm{q} 34 ; \mathrm{q} 11)$ $[4] / 53, \mathrm{XY},+2,+4,+5, \mathrm{t}(9 ; 22)(\mathrm{q} 34 ; \mathrm{q} 11),+11,+14,+21,+\operatorname{der}(22)$ $\mathrm{t}(9 ; 22)(\mathrm{q} 34 ; \mathrm{q} 11)[14] / 46, \mathrm{XY}[2]$.

There was presence of two clones of the abnormal cells; one with normal chromosome complement and Philadelphia chromosome, while other with hyper diploid complement and double Philadelphia. FISH analysis using dual color dual fusion BCR-ABL probe substantiated the presence of the BCR$A B L$ rearrangement along with an extra fusion signal showing 


\section{Open Access Blood Research \& Transfusion Journal}

presence of supernumerary Philadelphia in $\geq 70 \%$ of the analyzed cells (Figure 1). Analysis of the cerebrospinal fluid showed absence of malignant cells. After one month induction treatment with vincristine, daunorubicin, L-asparaginase, prednisone and imatinib, complete hematological remission was never achieved and patient succumbed to his disease.
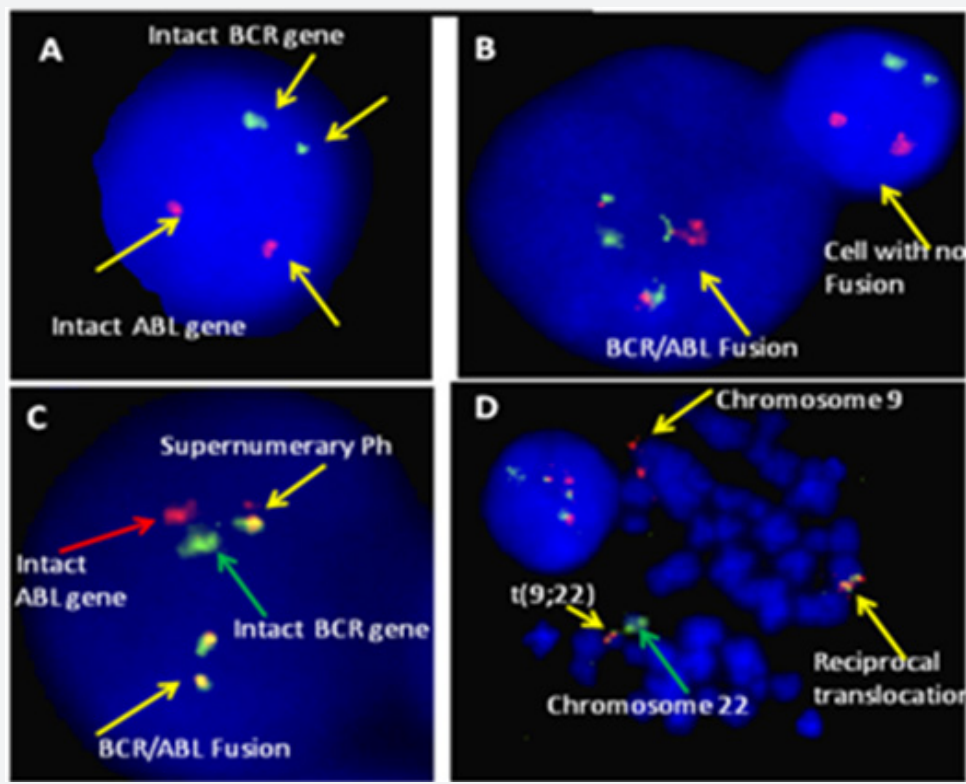

Figure 1: Interphase and metaphase FISH with BCR/ABL dual colour dual fusion probe: (A) Control Nucleus showing 2 green and 2 orange signals from chromosome 22 (BCR breakpoint) and chromosome 9 (ABL breakpoint). (B) Patient's sample nuclei showing intact breakpoints and $B C R / A B L$ fusion $(C)$ supernumerary Philadelphia $(\mathrm{Ph})$ chromosome (extra yellow signal) with $B C R / A B L$ gene rearrangement $(D)$ metaphase showing one intact chromosome 9, one intact chromosome 22 and reciprocal translocation $\mathrm{t}(9 ; 22)$ giving rise to Philadelphia chromosome.

\section{Discussion}

Cytogenetic has yielded significant insight to the importance of cytogenetic abnormalities in the path physiology and prognosis of hematologic malignancies [6]. Presence of double Philadelphia is common in CML, with over five hundred reported cases, but is rare in ALL. A total of 66 cases with double Ph are reported in Mitelman's Catalogue of Chromosome Aberrations in Cancer. Out of those, only 23 cases were associated with hyper diploidy and on conventional karyotyping, only three cases showed more than two copies of the Ph chromosome [7]. Another study reported a series of $66 \mathrm{Ph}+\mathrm{ALL}$ patients in which, eight cases were double $\mathrm{Ph}$ positive (12\%) but only three (9\%) were hyper diploid. They suggested that $\mathrm{Ph}+$ /hyper diploid karyotype achieve complete remission more readily than patients who did not have an additional hyper diploid karyotype [8].

In another series of 208 patients, out of $33 \mathrm{Ph}$ positive cases, twenty-two patients $(68.75 \%)$ had a pseudo diploid karyotype (46 chromosomes) at diagnosis, three patients (9.4\%) had 47 chromosomes (low hyper diploidy) and two (6.2\%) over 50 chromosomes (high hyper diploidy). They suggested association of Philadelphia with pseudo diploidy and higher rate of relapses [9]. Another study also reported that patient with hyper diploid karyotype showed improvement in survival as compared to those without additional hyper diploid karyotype. They also reported that the presence of an extra $\mathrm{Ph}$ chromosome is associated with a worse prognosis and relapse occurred in those patients who have extra sub clones at diagnosis [10]. These reports have indicated the genetic heterogeneity of Ph (+) ALL in adults could potentially translate into variable outcomes in different cases. High-hyper diploid ALL cases have shown that blasts have a marked propensity for apoptosis in vitro, which has been related to the relatively good in vivo response to chemotherapy. Reports from the literature also make it conceivable that the presence of high-hyper diploidy as an additional karyotypic abnormality may confer a better prognosis to $\mathrm{Ph}(+)$ ALL, presumably by altering the kinetics of $\mathrm{Ph}(+)$ neoplastic cells [11]. Chilton et al suggested, High-hyper diploidy is an important subtype of ALL at all ages and displays outcome heterogeneity according to chromosomal gain, however they did not find overall survival differences between $\mathrm{Ph}$-positive $\mathrm{HeH}$ patients and $\mathrm{Ph}$-negative patients ( $\mathrm{P}=0.2$ : 50 vs $57 \%$ at 5 years) [12].

\section{Conclusion}

In our case hematological remission was never achieved after induction chemotherapy and the patient finally died due to the refractory disease. So in our ALL case, major events were: presence of two different sub clones both containing Philadelphia, presence of supernumerary $\mathrm{Ph}$ and hyper diploidy along with trisomies of chromosomes. This report thus suggests 
that simultaneous presence of composite events and genetic heterogeneity might have a role in poor outcome.

\section{References}

1. Ritterbach J, Hiddemann W, Beck JD, Schrappe M, Janka-Schaub G, et al. (1998) Detection of hyper diploid karyotypes ( $>50$ chromosomes) in childhood acute lymphoblastic leukemia (ALL) using fluorescence in-situ hybridization (FISH). Leukemia 12(3): 427-433.

2. Anonymous (1996) Cytogenetic abnormalities in adult acute lymphoblastic leukemia: correlations with hematologic findings outcome. A Collaborative Study of the Group Francais de Cytogenetique Hematologique. Blood 87(8): 3135-3142.

3. Faderl S, Kantarjian HM, Thomas DA, Cortes J, Giles F, et al. (2000) Outcome of Philadelphia chromosome-positive adult acute lymphoblastic leukemia. Leuk Lymphoma 36(3-4): 263-273.

4. Tauro S, McMullan D, Griffiths M, Craddock C, Mahendra P (2003) High-hyperdiploidy in Philadelphia positive adult acute lymphoblastic leukaemia: case-series and review of literature. Bone Marrow Transplant 31(9): 763-766.

5. Shaffer LG, Tommerup N (2005) Recommendations of the International Standing Committee on Human Cytogenetic Nomenclature. Published in collaboration with 'Cytogenetic and Genome Research'. International System for Human Cytogenetic Nomenclature.

This work is licensed under Creative Commons Attribution 4.0 License

DOI: 10.19080/OABTJ.2017.01.555566
6. Faderl S, Kantarjian HM, Talpaz M, Estrov Z (1998) Clinical Significance of Cytogenetic Abnormalities in Adult Acute Lymphoblastic Leukemia. Blood 91(11): 3995-4019.

7. Mitelman F (2002) Catalog of chromosome Aberrations in Cancer.

8. Rieder H, Ludwig WD, Gassmann W, Maurer J, Janssen JW, et al. (1996 ) Prognostic significance of additional chromosome abnormalities in adult patients with Philadelphia chromosome positive acute lymphoblastic leukaemia. Br J Haematol 95(4): 678-691.

9. De Braekeleer E, Douet GN, Morel F (2010) Philadelphia chromosomepositive acute lymphoblastic leukemia: a cytogenetic study of 33 patients diagnosed between 1981 and 2008. Anticancer Res 30: 569573.

10. Thomas X, Thiebaut A, Olteanu N, Danaïla C, Charrin C, et al. (1998) Philadelphia chromosome positive adult acute lymphoblastic leukemia: characteristics, prognostic factors and treatment outcome. Hematol Cell Ther 40(3): 119-128.

11. Tauro S, McMullan D, Griffiths M, Craddock C, Mahendra P (2003) High-hyper diploidy in Philadelphia positive adult acute lymphoblastic leukaemia: case-series and review of literature. Bone Marrow Transplant 31(9): 763-766.

12. Chilton L, Buck G, Harrison CJ, Ketterling RP, Rowe JM, et al. (2014) High hyper diploidy among adolescents and adults with acute lymphoblastic leukaemia (ALL): cytogenetic features, clinical characteristics and outcome. Leukemia 28(7): 1511-1518.

\section{Your next submission with Juniper Publishers will reach you the below assets}

- Quality Editorial service

- Swift Peer Review

- Reprints availability

- E-prints Service

- Manuscript Podcast for convenient understanding

- Global attainment for your research

- Manuscript accessibility in different formats

( Pdf, E-pub, Full Text, Audio)

- Unceasing customer service

Track the below URL for one-step submission https://juniperpublishers.com/online-submission.php 